\title{
Expression of Fas and Fas ligand protein and mRNA in mouse oocytes and embryos
}

\author{
R. L. Kelkar, S. J. Dharma and T. D. Nandedkar* \\ National Institute for Research in Reproductive Health, JM Street, Parel, Mumbai-400012, India
}

\begin{abstract}
During mammalian embryonic development, abnormal eggs and embryos are eliminated by apoptosis; however, the precise apoptotic pathways remain as yet unidentified. In the present study, expression of Fas and Fas ligand the proximal members of the death receptor pathway, was evaluated in mouse preimplantation embryos by immunofluorescence and in situ hybridization techniques. Ovulated oocytes were collected from oviducts of cyclic mice on the day of oestrus (day 0), and one-cell, twocell embryos and eight-cell morulae were collected from oviducts of mated animals on days 1, 2 and 3 of pregnancy, respectively. Blastocysts were flushed from the uterine horns on day 4. Expression of Fas and Fas L mRNAs and
\end{abstract}

proteins was absent from embryos at days $\mathbf{0 ,} 1$ and 2 . A marked increase in Fas and Fas L mRNA and protein expression was detected in all morphologically normal embryos on day 3 and day 4 . In addition, embryos on days 3 and 4 were positive for terminal deoxynucleotidyl transferase-mediated dUTP nick-end labelling (TUNEL) staining; however, absence of caspase 8 and 3 and intense localization of proliferating cell nuclear antigen confirmed the proliferative status of these embryos. Furthermore, TUNEL staining was absent in postimplantation embryonic sections obtained on day 6 . The results of the present studies thus indicate an equilibrium between proliferation and apoptosis in the preimplantation embryo.

\section{Introduction}

Apoptosis is a process of selective and programmed death of cells occurring in almost all tissues (Kerr et al., 1972) and is finely regulated by a number of genes and gene products. Morphological and biochemical studies have shown that the demise of both somatic and germ cells in ovarian follicular atresia is mediated by apoptosis (Hughes and Gorospe, 1991; Morita and Tilly, 1999).

In contrast to atretic follicles, apoptotic processes seem to be dormant in follicles destined to ovulate. However, after ovulation and fertilization, these cell death processes are activated during preimplantation development (Warner et al., 1998). Studies in mice, rats and humans have demonstrated that isolated cells in the inner cell mass as well as the trophectoderm are eliminated by apoptosis (Hardy, 1997, 1999; Pampfer and Donnay, 1999), which is under the regulatory control of growth factors (Brison and Schultz, 1997; Byrne et al., 2002). The function of this cell death may be to control the number of developing embryos, to eliminate abnormal embryos or trim excess or dysfunctional stem cells. The expression of caspases and Bcl2 family members has been reported in mouse preimplantation embryos (Jurisicova et al., 1998; Exley et al., 1999), indicating an involvement of this mitochondrial pathway

*Correspondence

Email: cellbioirr@hotmail.com of cell death in embryo demise. Similarly, expression of mRNA encoding Fas and Fas $L$ has been demonstrated in rat and human preimplantation embryos by RT-PCR (Kawamura et al., 2001). However, the precise pathways governing this phenomenon of embryonic apoptosis remain unknown.

Fas (48 kDa) is a cell membrane integral glycoprotein similar to tumour necrosis factor $\alpha$ receptor (TNF $\alpha-R)$, and its ligand (Fas L) is a type II membrane protein homologous to TNF- $\alpha$. Apoptosis is induced in Fasbearing cells when Fas $L$ binds to Fas. This interaction results in the activation of the Fas-associated death domain (FADD), which in turn forms a docking site to facilitate the autocatalytic activation of procaspase 8 (Chinnaiyan et al., 1995; Nagata and Goldstein, 1995; Ashkenazi and Dixit, 1999). Once activated, caspase 8 can stimulate other downstream proteases such as caspase 3. These proteolytic effectors of cell death cleave key cellular substrates, thereby disorganizing the cellular assembly and executing apoptosis (Thornberry et al., 1997; Thornberry and Lazebnik, 1998).

In the present study, the expression of Fas and Fas L and the mRNA encoding them has been studied in mouse oocytes after ovulation and after fertilization in embryos up to the blastocyst stage. Apoptosis was detected by terminal deoxynucleotidyl transferase-mediated dUTP nick-end labelling (TUNEL) (Gavrielli et al., 1992) and immunohistochemical localization of caspases 8 and 3 . Proliferating cell nuclear antigen (PCNA) is a protein 
expressed during the S-phase of the cell cycle and is involved in DNA replication and repair (Kelman, 1997). Immunolocalization of PCNA has been used in a number of studies as an index of proliferation and in the present study was used to assess the proliferative status of the embryos (Hall et al., 1990; Leibovici et al., 1992). The results indicate a role for the Fas-Fas $L$ signalling system in preimplantation embryo development.

\section{Materials and Methods}

\section{Animals}

Swiss mice bred from the animal colony at the National Institute for Research in Reproductive Health were maintained at constant light $(12 \mathrm{~h}$ light: $12 \mathrm{~h}$ dark), temperature $\left(24^{\circ} \mathrm{C}\right)$ and humidity $(60 \%)$, and were supplied with food and water ad libitum. The animal requirement for the present study was approved by the Institutional Animal Ethics Committee and experiments were performed in accordance with the guidelines set by the Committee for the Purpose of Control and Supervision of Experiments on Animals, India.

\section{Collection of oocytes, eggs and embryos}

Vaginal smears of adult female Swiss mice aged 2.5-3.0 months were monitored daily. After assessing normal cyclicity of 4-5 days for three consecutive cycles, animals were killed by decapitation on the day of oestrus (day 0 ) and oviducts were teased to obtain ovulated oocytes with cumulus mass.

For collection of embryos, female mice were cohabitated with males and the day of appearance of vaginal plug was considered as day 1 of pregnancy. Fertilized eggs, two-cell embryos and morulae were retrieved from the oviduct on days 1, 2 and 3 of pregnancy, respectively, and blastocysts were flushed from the uterine horns on day 4 using $0.01 \mathrm{~mol} \mathrm{PBS} \mathrm{I}^{-1}$. The oocytes and embryos at the various stages (days $0-4$ ) were fixed on slides coated with silane for in situ hybridization or slides coated with poly-L-lysine (Sigma, St Louis, MO) for indirect immunofluorescence and immunohistochemistry. Each group consisted of 10 animals and 5-10 embryos were recovered per animal.

\section{Post-implantation embryonic sections}

Five animals were administered 1\% (w/v) Evan's blue in saline through the tail vein on day 6 of pregnancy and were autopsied after $5 \mathrm{~min}$. The implantation sites were cut and $10 \mu \mathrm{m}$ sections taken on Leitz cryostat were mounted on silanated slides for TUNEL staining.

\section{In situ hybridization}

Unfertilized oocytes at day 0 and fertilized embryos at days $1,2,3$ and 4 were fixed on slides in $4 \%(\mathrm{w} / \mathrm{v})$ paraformaldehyde in PBS for 20 min at room temperature $\left(25^{\circ} \mathrm{C}\right)$ and then were treated with proteinase $\mathrm{K}(10$ $\left.\mu \mathrm{g} \mathrm{ml} \mathrm{l}^{-1}\right)$ in Tris-EDTA buffer $\left(\mathrm{pH} \mathrm{7.6)}\right.$ at $37^{\circ} \mathrm{C}$ for 30 min. In situ hybridization was performed for Fas and Fas ligand as described by Nandedkar and Dharma (2001). The oligoprobe sequences selected for Fas-Fas ligand mRNA localization in the present study were taken from Roughton et al. (1999). These oligoprobes were tail-labelled with Digoxigenin Oligonucleotide Tailing Kit (Roche Molecular Biochemicals, Mannheim). Briefly, after washing in PBS $\left(0.1 \mathrm{~mol} \mathrm{I}^{-1}\right)$, the slides were incubated in sodium saline citrate $(2 \times$ SSC) for $10 \mathrm{~min}$. Prehybridization was carried out at room temperature for $1 \mathrm{~h}$ in prehybridization cocktail. Overnight hybridization at $42^{\circ} \mathrm{C}$ was performed with digoxigenin-labelled cDNA antisense and sense oligoprobes dissolved in the prehybridization mixture at a concentration of 0.5 pmol $\mu l^{-1}$. After stringent post-hybridization washings with various concentrations of SSC and incubation in Tris buffer $(\mathrm{pH} \mathrm{7.4)}$ for $10 \mathrm{~min}$, the slides were blocked with $2 \%(\mathrm{v} / \mathrm{v})$ normal sheep serum in Tris buffer containing $0.3 \%(\mathrm{v} / \mathrm{v})$ Triton X-100 (Sigma) for $1 \mathrm{~h}$ at room temperature. Sections were incubated overnight in alkaline phosphatase-conjugated anti-digoxigenin antibody (1:500 dilution; Roche). The next day, slides were washed twice in Tris buffer for 5 min each. Colour reaction was carried out by incubating all embryos and sections in a mixture of nitro-blue tetrazolium (NBT; Roche) and 5-bromo 4-chloro 3-indolyl phosphate (BCIP; Roche) for $20 \mathrm{~min}$ at room temperature in the dark. Levamisole $(0.2 \%(\mathrm{w} / \mathrm{v})$; Sigma) was added in the colour mixture to block endogenous phosphatases. After a wash in distilled water, slides were mounted in aquamount and viewed. The representative areas were photographed under bright field. The slides were subjected to an identical procedure using digoxigenin-labelled sense probes to provide negative controls.

\section{Immunofluorescence}

Ovulated oocytes and embryos were fixed in acetone at $-20^{\circ} \mathrm{C}$ for $10 \mathrm{~min}$, mounted on poly-L-lysine-coated slides and air dried. After washing in PBS, the specimens were permeabilized by incubating in $0.01 \%(\mathrm{v} / \mathrm{v})$ Triton$X 100$ (Sigma) in PBS for $5 \mathrm{~min}$ and then incubating $3 \%(\mathrm{w} / \mathrm{v})$ non-fat dried milk in PBS for 30 min to block non-specific binding. Slides were then incubated with primary antibody $\left(5 \mu \mathrm{g} \mathrm{ml}^{-1}\right)$ of either hamster antimouse Fas or Fas L monoclonal antibody (Pharmingen, San Diego, CA) overnight at $4^{\circ} \mathrm{C}$. Controls were incubated in $1 \%(\mathrm{v} / \mathrm{v}) \mathrm{SP}_{2} \mathrm{O}$ culture supernatants in PBS. After PBS washes, secondary antibody (R-phycoerythrin conjugated mouse anti-hamster IgG; Pharmingen) was applied at a dilution of 1:1000 in the dark at room temperature for $1 \mathrm{~h}$. Slides were washed in distilled water, air dried, mounted in glycerol and observed under blue light (Carl Zeiss, Gottingen). Photographs were taken at a magnification $\times 400$ using a 400ASA Kodak colour film. 
Table 1. Staining intensities for Fas mRNA and protein in mouse embryos

\begin{tabular}{lccccc}
\hline & Day 0 & Day 1 & Day 2 & Day 3 & Day4 \\
\hline $\begin{array}{l}\text { Fas mRNA } \\
\text { (in situ hybridization) }\end{array}$ & 0.1166 & 0.1836 & 0.2074 & 0.4291 & 0.6154 \\
$\begin{array}{l}\text { Fas protein } \\
\text { (indirect immunofluorescence) }\end{array}$ & 0.0691 & 0.0769 & 0.0719 & 0.6560 & $0.1931)$ \\
& & & & 0.6955 \\
\end{tabular}

Results are expressed in terms of mean absorbance.

Figures in parentheses indicate values for negative controls.

\section{DNA fragmentation detected by TUNEL}

DNA fragmentation in embryos at days 0,1 and 4 and in postimplantation embryonic sections taken on day 6 was detected using the non-radioactive detection method described by Gavrielli et al. (1992). The specimens were fixed in $1 \%(\mathrm{w} / \mathrm{v})$ paraformaldehyde in PBS for $20 \mathrm{~min}$ at room temperature and washed twice in PBS. The slides were then incubated in Proteinase $\mathrm{K}\left(20 \mu \mathrm{g} \mathrm{ml}^{-1}\right)$ for 15 min at $37^{\circ} \mathrm{C}$ and washed in PBS. The labelling of $3^{\prime}$ ends of fragmented DNA with digoxigenin was facilitated using terminal transferase (Tdt; Roche) after incubation of slides in terminal transferase buffer for $10 \mathrm{~min}$ at room temperature. Reaction mixture (Roche) containing $200 \mathrm{mmol}$ potassium cacodylate $\mathrm{I}^{-1}, 5 \mathrm{mmol} \mathrm{CoCl}_{2} \mathrm{I}^{-1}$, $1 \cup$ terminal transferase $\mu I^{-1}, 1 \mu \mathrm{mol}$ dig dUTP $\left.\right|^{-1}$ and $49 \mu \mathrm{mol}$ dideoxyATP $\mathrm{I}^{-1}$ was applied to the specimens for $2 \mathrm{~h}$ at $37^{\circ} \mathrm{C}$ in a humidified chamber. After three washes in Tris buffer, the slides were incubated in blocking buffer $\left(100 \mathrm{mmol}\right.$ Tris $\mathrm{I}^{-1}, 150 \mathrm{mmol}$ $\mathrm{NaCl} \mathrm{I}{ }^{-1}, \mathrm{pH} 7.5$ and $\%$ (w/v) blocking reagent) for $1 \mathrm{~h}$ at room temperature before addition of antidigoxigenin antibody conjugated to alkaline phosphatase. After incubation with antidigoxigenin antibody $1: 10000$ in $2 \%$ blocking solution; Roche) at $4{ }^{\circ} \mathrm{C}$ overnight in a humidified chamber the slides were washed twice in Tris buffer (pH 7.5) and finally equilibrated in alkaline phosphatase buffer (100 mmol Tris I I ${ }^{-1}, 150 \mathrm{mmol} \mathrm{NaCl} \mathrm{I}{ }^{-1}, 50 \mathrm{mmol}$ $\mathrm{MgCl}_{2} \mathrm{I}^{-1}, \mathrm{pH}$ 9.5). Enzyme substrate (33 $\mu \mathrm{g}$ NBT ml ${ }^{-1}$

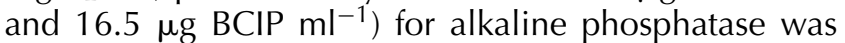
applied for colour development for $15 \mathrm{~min}$ in the dark. Colour reaction was terminated with $10 \mathrm{mmol}_{\text {Tris }} \mathrm{I}^{-1}$, 1 mmol EDTA I ${ }^{-1}$, $\mathrm{pH}$ 8.0. Blue-brown staining represented a positive reaction. Slides were observed and photographed under bright field using a Carl Zeiss microscope. Controls were processed in a similar manner with the omission of terminal transferase in the reaction mixture.

\section{Immunohistochemistry}

The primary antibodies used were mouse monoclonal antibodies to recombinant caspase 8, caspase 3 (Novocastra Laboratories, Newcastle-upon-Tyne) and PCNA (Santacruz Biotechnology, Santa Cruz, CA) at dilutions of 1:50 for caspases and 1:500 for PCNA. Specimens were fixed in acetone at $-20^{\circ} \mathrm{C}$ for $10 \mathrm{~min}$ and then incubated in $0.3 \%(\mathrm{v} / \mathrm{v}) \mathrm{H}_{2} \mathrm{O}_{2}$ in methanol at $-20^{\circ} \mathrm{C}$ for 30 min to block endogenous peroxidase activity. After
Table 2. Staining intensities for terminal deoxynucleotidyl transferase-mediated dUTP nick-end labelling (TUNEL) in mouse embryos

\begin{tabular}{lc}
\hline Stage of the embryo & Mean absorbance \\
\hline Day 3 & 0.4584 \\
Day 4 & 0.5530 \\
& $(0.2441)$ \\
Day 6 (embryo) & 0.1314 \\
& $(0.1715)$ \\
Day 6 (decidual cells) & 0.7292 \\
& $(0.2882)$ \\
\hline
\end{tabular}

Figures in parentheses indicate values for negative controls.

two PBS washes, non-specific binding was inhibited by incubation in 3\% (w/v) non-fat dried milk powder in PBS for $30 \mathrm{~min}$ at room temperature and primary antibody was applied overnight at $4^{\circ} \mathrm{C}$; controls were incubated in $1 \%(\mathrm{v} / \mathrm{v}) \mathrm{SP}_{2} \mathrm{O}$ culture supernatants. Slides were then washed in PBS and incubated with secondary antibody (rabbit anti-mouse IgG; Dako, Glostrup) at a dilution of $1: 1000$ for $1 \mathrm{~h}$ at room temperature. Colour was developed using $1 \%(\mathrm{w} / \mathrm{v})$ diaminobenzidine (Sigma) and $0.3 \%(\mathrm{v} / \mathrm{v}) \mathrm{H}_{2} \mathrm{O}_{2}$ in PBS as substrate mix. Slides were then washed in distilled water, mounted in Canada balsam and photographed at a magnification of $\times 400$.

\section{Quantitation by image analysis}

Photographs were scanned and comparisons of staining intensities for Fas and mRNA encoding Fas and of TUNEL in oocytes and embryos at various stages were made using Biovis Image Analysis Software (Expert Vision Laboratories, Mumbai). Results are expressed in terms of mean absorbance (Tables 1 and 2).

\section{Results}

Expression of Fas and Fas $L$ in oocytes and embryos by in situ hybridization and indirect

immunofluorescence

Expression of Fas and mRNA encoding Fas in unfertilized oocytes, fertilized eggs and embryos is shown (Fig. 1). On the day of estrus, day 0, eggs collected from the oviduct showed weak staining for Fas mRNA by in situ hybridization (Fig. 1a) and for Fas protein by immunofluorescence (Fig. 1g). However, the cumulus 


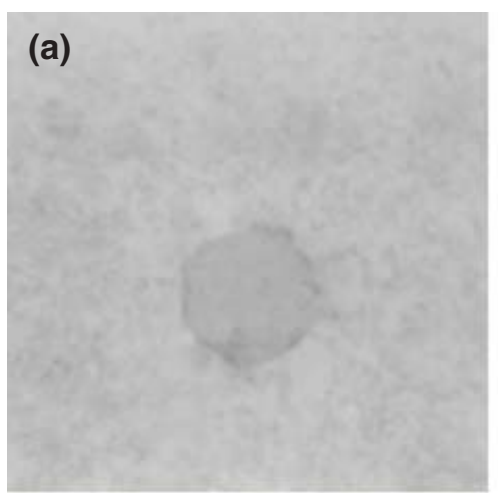

(d)

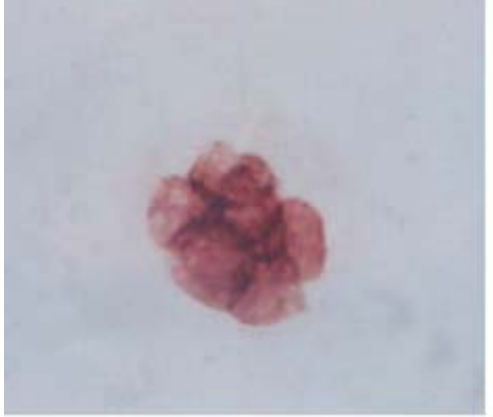

\section{(g)}
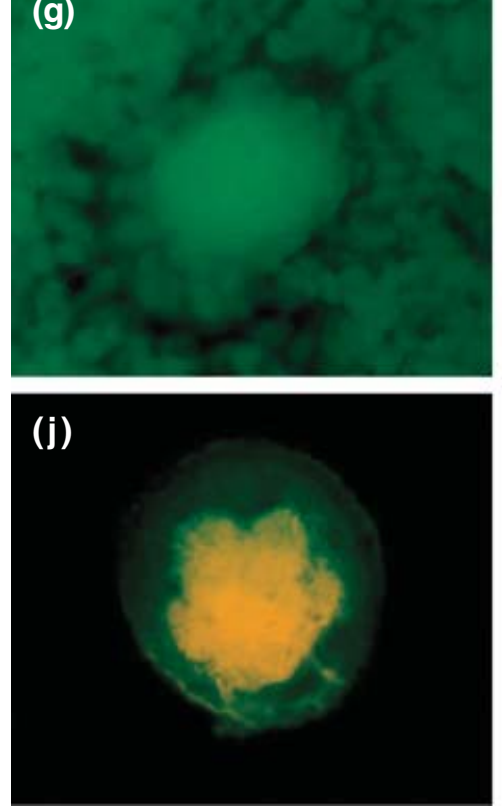

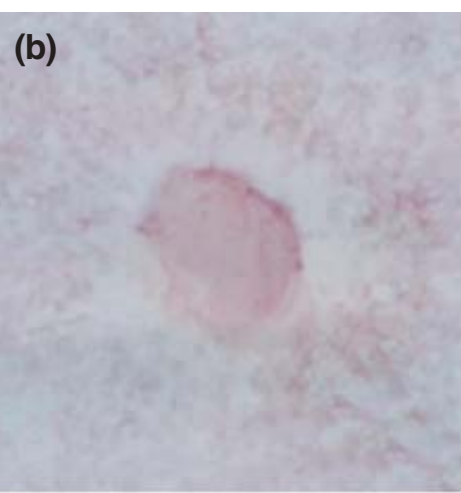

(e)

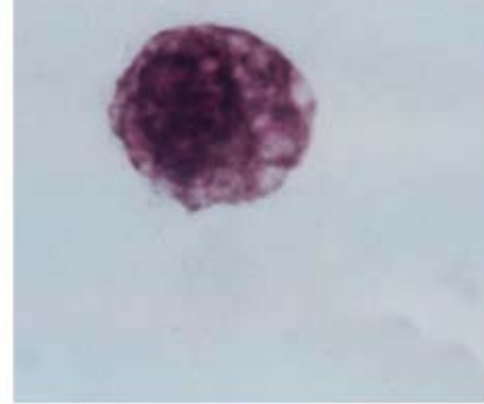

\section{(h)}

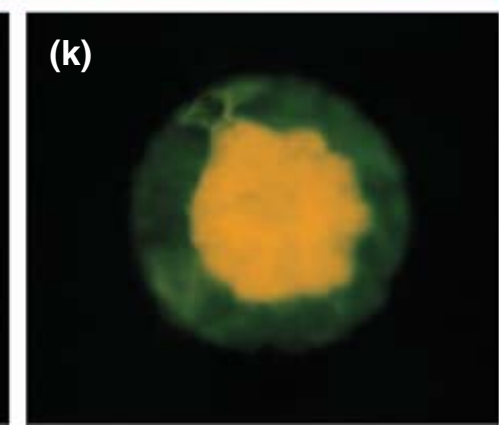

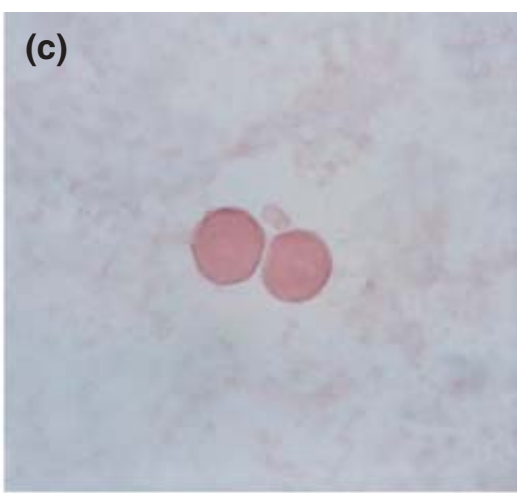

(f)

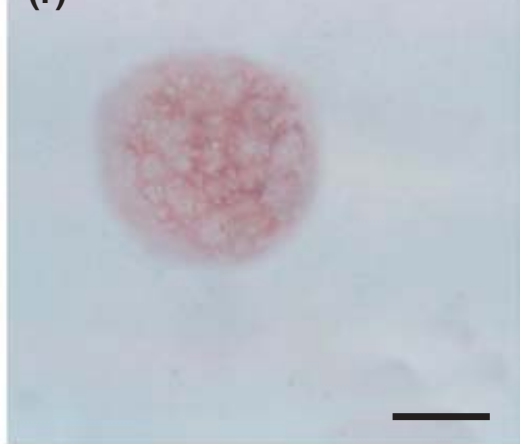

\section{(i)}
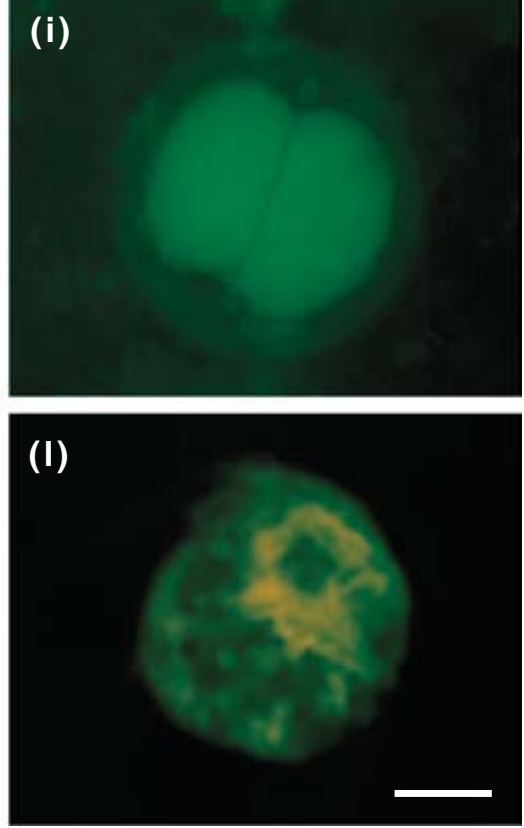

Fig. 1. Expression of Fas mRNA and protein in mouse oocytes and embryos by in situ hybridization (a-f) and immunofluorescence $(\mathrm{g}-\mathrm{l})$, respectively. Staining was weak in $(\mathrm{a}, \mathrm{g})$ ovulated oocytes on day $0,(\mathrm{~b}, \mathrm{~h})$ fertilized eggs on day 1 and $(\mathrm{c}, \mathrm{i})$ two-cell embryos on day 2 . There was a marked increase in both Fas and mRNA encoding Fas in $(\mathrm{d}, \mathrm{j})$ 8-16-cell embryos on day 3 and (e,k) blastocysts on day 4 as compared with $(\mathrm{f}, \mathrm{l})$ negative controls on day 4 . Scale bars represent (a-f) $10 \mu \mathrm{m}$ and (g-l) $16 \mu \mathrm{m}$.

granulosa cells were positive for the death receptor. Similarly, on the day of appearance of vaginal plug, day 1 , fertilized eggs obtained from the oviduct expressed Fas mRNA (Fig. 1b) and Fas (Fig. 1h); staining was weak in the zygote but moderate-to-intense in the dispersed cumulus cells. Staining for both Fas mRNA and protein was negligible in two-cell (day 2) embryos (Fig. 1c,i). On day 3 , a marked increase in expression of Fas mRNA 
(Fig.1d) and Fas (Fig. 1j) was observed in the morulae retrieved from the oviduct. Blastocysts recovered from the uterus on day 4 had 16-32 cells with intact zonae pellucidae. Intense expression similar to that observed at day 3 was observed in all morphologically normal embryos (Fig. 1e,k). The controls did not stain for Fas mRNA (Fig. 1f) and Fas (Fig. 1l).

Quantitation by image analysis is summarized (Table 1). The results confirmed a gradual increase in intensity for both Fas mRNA and Fas from day 0 to day 4 reaching a peak intensity on day 4 . The intensity for Fas mRNA increased $5-6$-fold $(0.1166$ at day 0 versus 0.6154 at day 4) whereas the intensity for Fas was 10 times higher (0.0691 at day 0 versus 0.6955 at day 4) during the embryonic development.

Similar results were obtained with Fas L, although the expression of mRNA and protein was lower than that of Fas (data not shown).

\section{Detection of DNA fragmentation by in situ 3' end labelling (TUNEL)}

One of the hallmarks of apoptotic cell death is internucleosomal DNA fragmentation. The TUNEL assay was used to detect 3'-hydroxy DNA fragments in mouse eggs and embryos. On day 0, ovulated oocytes were negative but cumulus cells were positive for TUNEL (Fig. 2a), indicating apoptosis in the cumulus cells but not in the oocyte. Similarly on day 1 of pregnancy, the zygote was negatively stained for TUNEL but most of the cumulus cells exhibited a positive reaction (Fig. 2b). However, day 3 morulae (Fig. 2c) and day 4 blastocysts (Fig. 2d) showed positive TUNEL reactions consistent with an increase in Fas and Fas L expression observed at these stages. Negative controls were processed in the absence of terminal transferase and did not show any staining (Fig. 2e,f)

The implanted embryo was negative for TUNEL but the decidual cells and the uterine epithelium showed a strong positive reaction, as observed in sections of implantation sites obtained on day 6 of pregnancy (Fig. 2g). Negative controls did not show any staining (Fig. 2h).

The quantitation of intensity for TUNEL is shown (Table 2). A slight increase in intensity for TUNEL was observed from day 3 to day 4 (0.4584 versus 0.5530 , respectively). However, on day 6 , the implanted embryo showed a low (0.1314) intensity but the decidual cells showed significantly high intensity (0.7292) for TUNEL.

\section{Immunohistochemical localization of PCNA and caspases 8 and 3}

Localization of PCNA and caspase 3 in ovulated oocytes (day 0) and preimplantation embryos recovered on day 4 is shown (Fig. 3). A weak positive immunoreaction for PCNA was detected in the oocyte but not in cumulus cells on day 0 (Fig. 3a) and an increase in the intensity of staining was observed in the day 4 blastocyst (Fig. 3c). Both trophectoderm and inner cell mass were positive for the proliferative marker. Control day 0 and day 4 embryos incubated in $\mathrm{SP}_{2} \mathrm{O}$ culture supernatants instead of primary antibody did not show any staining (Fig. 3b,d).

Caspase 3 was localized weakly in the oocyte as well as cumulus cells on day 0 (Fig. 3e), indicating initiation of apoptosis in these cells. However, no staining for caspase 3 could be detected in the blastocysts retrieved on day 4 (Fig. $3 g$ ) as compared with the negative controls (Fig. 3f,h). Similar results were obtained using a mouse monoclonal to caspase 8, the proximal caspase of the Fas-Fas L pathway (data not shown).

\section{Discussion}

In the present study, expression of Fas and Fas L, the pro-apoptotic members of the death receptor pathway was observed in mouse oocytes and embryos. On day 0, after ovulation, oocytes do not express Fas-Fas L. After fertilization, the egg continues to be negative for both Fas and Fas $L$ antigens on day 1 . Absence of Fas and Fas $L$ expression as observed by in situ hybridization confirmed these results. The cumulus cells demonstrated expression of Fas and Fas $L$ on day 1. After fertilization, the fate of these cumulus cells is cell death. TUNEL-positive staining in the cumulus cells but not in the fertilized egg confirms the presence of apoptotic processes in these cells.

Oocytes on day 0 and embryos on day 1 and day 2 did not express Fas and Fas L; however, embryos on day 3 and day 4 expressed both Fas and Fas L, mRNA and protein, and DNA fragmentation as indicated by TUNEL was also observed in embryos on day 1 and day 4 . These results indicate that apoptotic processes might be present in these developing embryos. However, (i) both TUNEL and Fas staining was observed consistently in all morphologically normal embryos retrieved, and (ii) day 4 embryos failed to express caspases 8 and 3 while intensely expressing the proliferation marker, PCNA. Therefore, the present observations could be explained by one or more of the following:

First, the membrane-anchored receptor Fas is activated by trimerization after ligand binding and facilitates caspase activation through adaptor proteins such as FADD or TNF- $\alpha$ receptor-associated death domain (TRADD) (Chinnaiyan et al., 1995; Nagata and Goldstein, 1995; Ashkenazi and Dixit, 1999). Earlier studies demonstrated that Fas expression may not always lead to apoptosis (Payne et al., 1999). In the present study, activation of caspase 3 antigen was not observed as revealed by immunohistochemical localization. Absence of caspase activation may be the result of alternative splice forms of Fas that lack either the death domain or the membraneanchoring sequences (Cascino et al., 1995, 1996) or lack of trimerization of the receptor. 

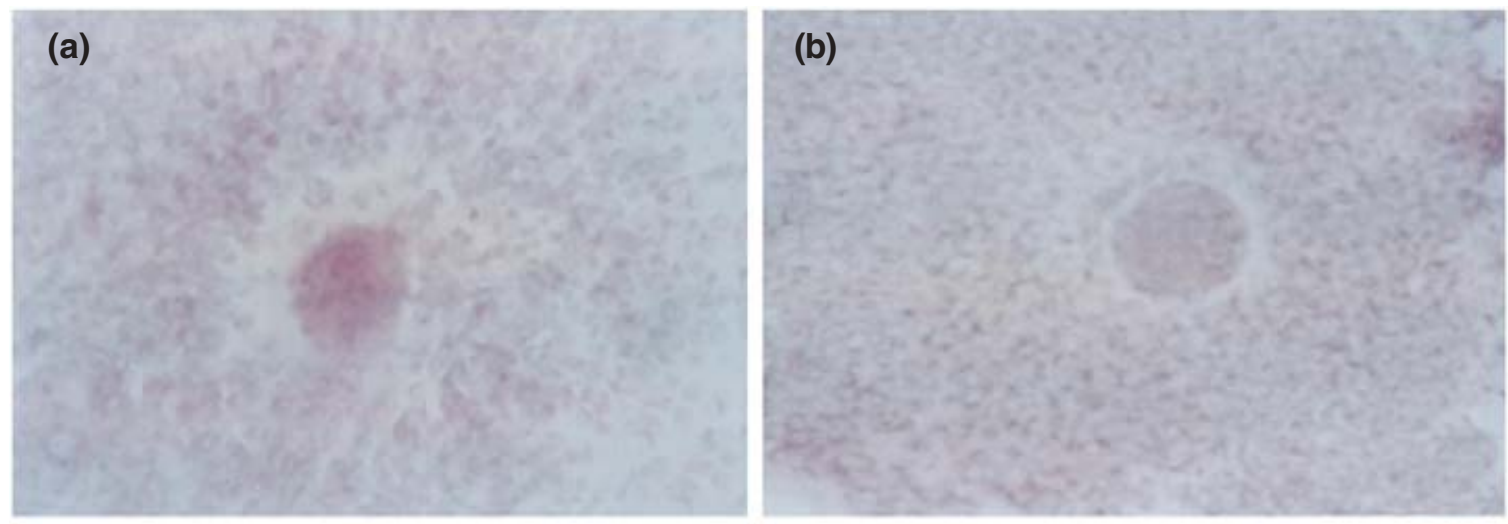

(c)

(d)
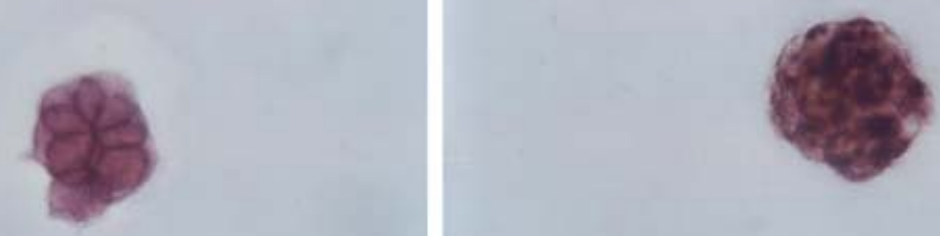

(e)

(f)

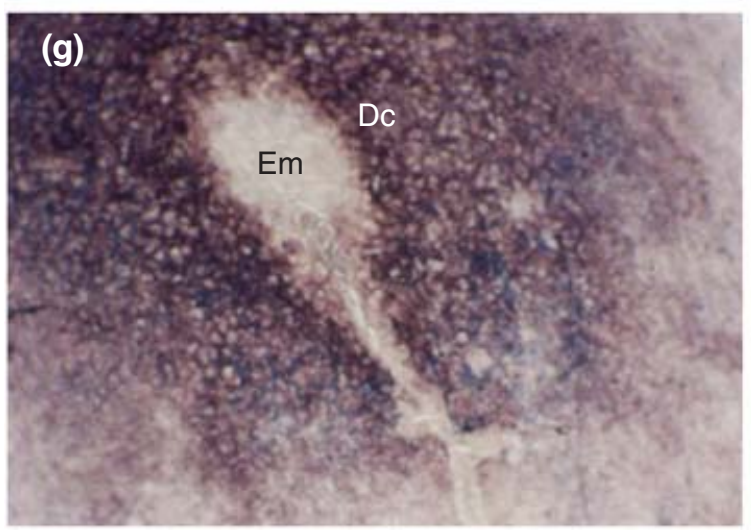

(h) Em

Dc

Fig. 2. Detection of apoptosis by terminal deoxynucleotidyl transferase-mediated dUTP nick-end labelling (TUNEL) assay in (a) ovulated oocyte, (b) fertilized egg and preimplantation embryos at (c) day 3 and (d) day 4 of pregnancy in mice. An increase in staining was observed at days 3 and 4. (e) Day 0 and (f) day 4 negative controls were processed in the absence of terminal tranferase. (g) Staining was not observed in postimplantation embryos (Em) sectioned on day 6 of pregnancy, whereas only decidual cells (Dc) were TUNEL-positive as compared with (h) negative controls. Scale bar represents $10 \mu \mathrm{m}$. 

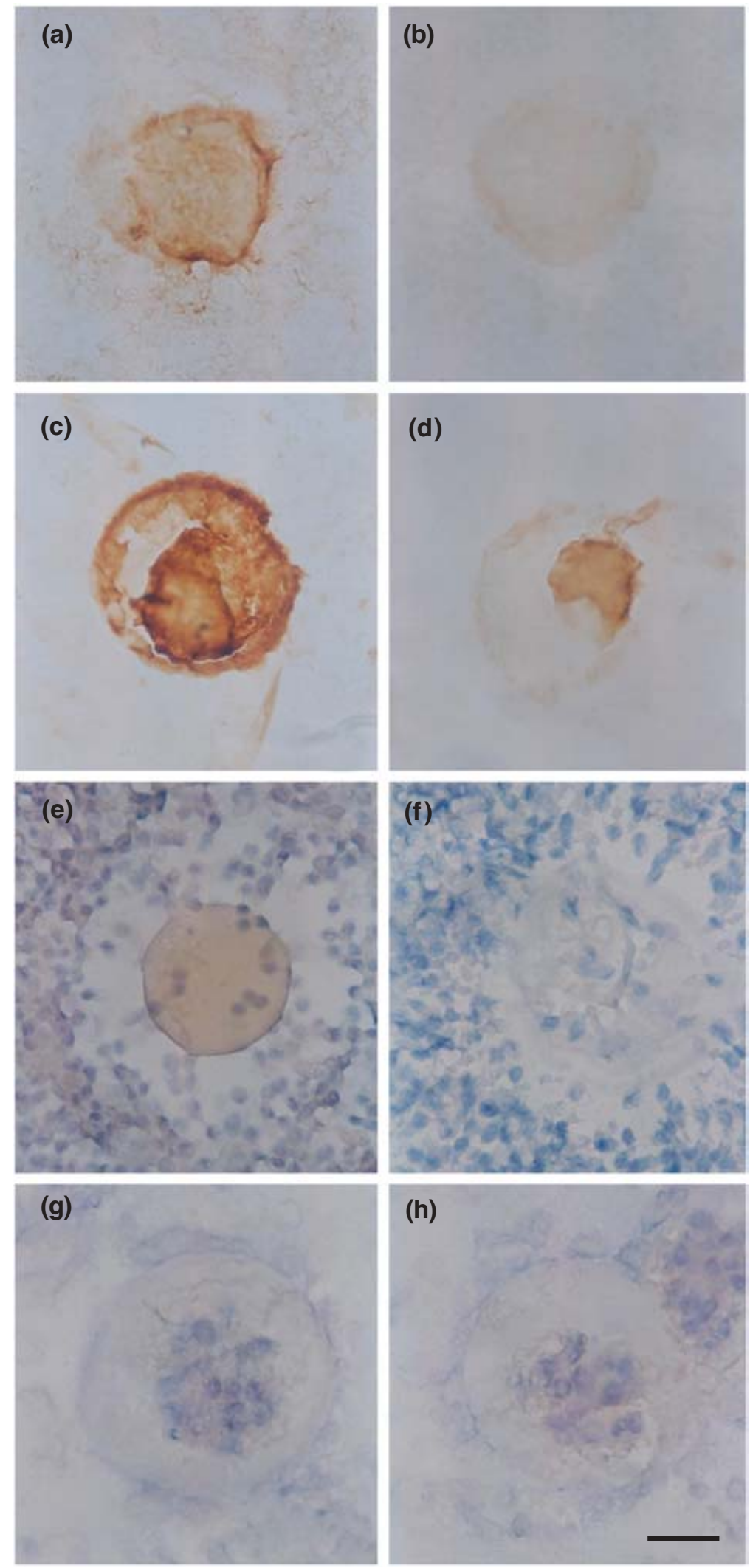

Fig. 3. Immunolocalization of (a-d) proliferating cell nuclear antigen (PCNA) and (e-h) caspase 3 in ovulated oocytes on day 0 and blastocysts on day 4 of pregnancy. (a) Positive staining for PCNA observed in oocytes but not cumulus cells at day 0 and (c) intense staining is observed in embryos at day 4. (b,d) No staining was observed in negative controls. Weak caspase 3 expression was detected in (e) oocyte and cumulus cells at day 0 but not in (g) blastocysts at day 4 as compared with negative controls at (f) day 0 and (h) day 4 . Scale bar represents $16 \mu \mathrm{m}$. 
Second, an increasing number of studies have reported false positive results with TUNEL in cardiac myocytes (Kanoh et al., 1999), in mouse kidney and liver cells (Pullkkanen et al., 2000) and histological sectioning (Sloop et al., 1999). A similar possibility cannot be denied in case of this study yielding intense TUNEL staining in all normal embryos.

In contrast to the above two conditions, in which it is assumed that no apoptosis occurs in spite of Fas expression or positive TUNEL staining, numerous studies can be cited that demonstrate apoptosis in developing embryos (Hardy 1997, 1999; Warner et al., 1998; Pampfer and Donnay, 1999). Therefore, it is probable that, in the present study, apoptosis is indeed triggered in the developing embryos. However, there is a balance between proliferation and cell death as indicated by a strong immunoreaction to the PCNA antibody seen in day 4 blastocysts. The results of the present study are in agreement with those of Makarevich and Markkula (2002) who demonstrated colocalization of PCNA and TUNEL-positive cells in bovine blastocysts, indicating an involvement of PCNA in DNA repair processes in TUNEL-positive cells. Thus, the PCNA may be involved in DNA repair (Warbrick, 2000) and therefore the rescue of the preimplantation embryo from undergoing apoptosis so as to facilitate implantation. The rescue of the implanting embryo from apoptosis is confirmed through the present observations in day 6 embryonic sections that TUNEL staining is seen in the decidual cells of the endometrium but not in the implanted embryo.

Another important factor in rescuing the embryo from apoptosis is the action of growth factors. Studies in vitro in mouse (Brison and Schultz, 1997; Byrne et al., 2002) and bovine (Makarevich and Markkula, 2002) embryos indicate that factors such as insulin-like growth factor I (IGF-I), IGF-II and transforming growth factor $\alpha$ (TGF- $\alpha$ ) act as survival factors for the developing embryo. Thus, growth factors secreted by the endometrium around implantation may play a role in inhibiting embryonic apoptosis.

Furthermore, the increased concentrations of oestradiol that occur before implantation are essential for the preparation of receptive endometrium for the attachment of the blastocyst (Shelesnyak and Kraicer, 1963). Oestrogen is an anti-apoptotic agent (Hseuh et al., 1994) and is able to rescue the blastocyst from apoptosis and propel it towards implantation. Therefore, it seems probable that the TUNEL-positive day 4 blastocyst is rescued after the peak oestrogen concentrations and can implant on day 5 and thus, on day 6 , the implanted embryo is TUNEL-negative. Therefore, a failure of oestradiol secretion from the ovary or blockage by anti-oestrogens can cause degeneration of embryos and failure of implantation. The preovulatory LH surge has been reported to reactivate-retrieve the TUNEL-positive cells (Richards, 2001). Therefore, a role for gondotrophins and steroids in embryonic development, apoptosis and implantation is proposed.

In conclusion, the blastocyst on day 4 is positive for TUNEL and the death receptor Fas. However, the blastocyst also expresses PCNA and is negative for caspase 3, which is the terminal protease in the apoptotic cascade. Thus, the present studies indicate a balance between apoptosis and proliferation in the developing preimplantation embryo.

The authors thank the Director, NIRRH for his support and the Lady Tata Memorial Trust, Mumbai, for financial assistance. The technical help of S. M. Rewadekar and S. T. Ghanekar and the typing assistance of D. L. D'Souza are acknowledged.

\section{References}

Ashkenazi A and Dixit VM (1999) Apoptosis control by death and decoy receptors Current Opinion in Cell Biology 11 255-260

Brison DR and Schultz RM (1997) Apoptosis during mouse blastocyst formation: evidence for a role for survival factors including transforming growth factor alpha Biology of Reproduction 56 10881096

Byrne AT, Southgate J, Brison DR and Leese HJ (2002) Effects of insulin-like growth factors I and II on tumour necrosis factor alpha induced apoptosis in early murine embryos Reproduction Fertility and Development 14 79-83

Cascino I, Fiucci G, Papoff G and Ruberti G (1995) Three functional soluble forms of the human apoptosis-inducing Fas molecule are produced by alternative splicing Journal of Immunology 154 2706-2713

Cascino I, Papoff G, De Maria R, Testi R and Ruberti G (1996) Fas/Apo-1 (CD-95) receptor lacking the intracytoplasmic signalling domain protects tumor cells from Fas-mediated apoptosis Journal of Immunology 156 13-17

Chinnaiyan AM, O'Rourke K, Tewari M and Dixit VM (1995) FADD, a novel death domain containing protein interacts with the death domain of Fas and initiates apoptosis Cell 81 505-512

Exley GE, Tang C, McElhinny AS and Warner CM (1999) Expression of caspase and $\mathrm{BCl}-2$ apoptotic family members in mouse preimplantation embryos Human Reproduction 61 231-239

Gavrielli Y, Sherman Y and Ben-Sasson SA (1992) Identification of programmed cell death in situ via specific labelling of nuclear DNA fragmentation Journal of Cell Biology 119 493-501

Hall PA, Levison DA, Woods AL et al. (1990) Proliferating cell nuclear antigen (PCNA) immunolocalization in paraffin sections: an index of cell proliferation with evidence of deregulated expression in some neoplasms Journal of Pathology 162 285-294

Hardy K (1997) Cell death in mammalian blastocyst Molecular Human Reproduction 3 919-925

Hardy K (1999) Apoptosis in the human embryo Reviews of Reproduction 4 125-134

Hseuh AJW, Billig $\mathbf{H}$ and Tsafiri A (1994) Ovarian follicle atresia: a hormonally controlled apoptotic process Endocrine Reviews 15 707724

Hughes FMJ and Gorospe WC (1991) Biochemical identification of apoptosis (programmed cell death) in granulosa cells: evidence for a potential mechanism underlying follicular atresia Endocrinology 129 2415-2422

Jurisicova A, Latham KE, Casper RF and Varmuza SL (1998) Expression and regulation of genes associated with cell death during murine preimplantation embryo development Molecular Reproduction and Devopment 51 243-253

Kanoh M, Takemura G, Miaso J et al. (1999) Significance of myocytes with positive DNA in situ nick end-labeling (TUNEL) in hearts with dilated cardiomyopathy: not apoptosis but DNA repair Circulation $992757-$ 2764 
Kawamura K, Fukuda J, Kodama H, Kumagai J, Kumagai A and Tanaka T (2001) Expression of Fas and Fas ligand mRNA in rat and human preimplantation embryos Molecular Human Reproduction 75 431-436

Kelman Z (1997) PCNA: structure, functions and interactions Oncogene 16 629-640

Kerr JF, Wyllie AH and Currie AR (1972) Apoptosis: a basic biological phenomenon with wide ranging implications in tissue kinetics British Journal of Cancer 26 239-257

Leibovici M, Mond G, Geraudie J, Bravo R and Mechali M (1992) Nuclear distribution of PCNA during embryonic development in Xenopus laevis: a reinvestigation of early cell cycles Journal of Cell Science 102 63-69

Makarevich AV and Markkula M (2002) Apoptosis and cell proliferation potential of bovine embryos stimulated with insulin-like growth factor I during in vitro maturation and culture Biology of Reproduction 66 386-392

Morita Y and Tilly JL (1999) Oocyte apoptosis: like sand through an hour glass Developmental Biology 213 1-17

Nagata S and Goldstein P (1995) The Fas death factor Science 2671449 1456

Nandedkar TD and Dharma SJ (2001) Expression of bcl-xs and c-myc in atretic follicles of mouse ovary Reproductive Biomedicine 3 221-225

Pampfer S and Donnay I (1999) Apoptosis at the time of embryo implantation in mouse and rat Cell Death and Differentiation 6 533545

Payne SG, Smith SC, Davidge ST, Baker PN and Guilbert LJ (1999) Death receptor Fas/Apo-1/CD95 expressed by human placental cytotrophoblasts does not mediate apoptosis Biology of Reproduction 601144 1150

Pulkkanen KJ, Laukkanen MO, Naarala J and Yla-Herttuala S (2000) False positive apoptosis signal in mouse kidney and liver detected with TUNEL assay Apoptosis 5 329-333
Richards JS (2001) Perspective: the ovarian follicle - a perspective in 2001 Endocrinology 142 2184-2193

Roughton SA, Lareu RR, Bittles AH and Dharmarajan AM (1999) Fas and Fas ligand messenger ribonucleic acid and protein expression in the rat corpus luteum during apoptosis mediated luteolysis Biology of Reproduction 60 797-804

Shelesnyak MC and Kraicer PF (1963) The role of estrogen in nidation. In Delayed Implantation pp 265-280 Ed. AC Enders. University of Chicago Press, Chicago

Sloop GS, Roa JC, Delgado AG, Balart JT, Hines MO, III and Hill JM (1999) Histologic sectioning produces TUNEL reactivity. A potential cause of false positive staining Archives of Pathology and Laboratory Medicine 123 529-532

Thornberry NA and Lazebnik (1998) Caspases: enemies within Science $\mathbf{2 8 1}$ 1312-1216

Thornberry NA, Rano TA, Peterson EP et al. (1997) A combinatorial approach defines specificities of members of the caspase family and granzyme B. Functional relationships established for key mediators of apoptosis Journal of Biological Chemistry 27217 907-17 911

Warbrick E (2000) The puzzle of PCNA's many partners Bioessays $22997-$ 1006

Warner CM, Cao W, Exley GE, McElhinny AS, Alikani M, Cohen J, Scott RT and Brenner CA (1998) Genetic regulation of egg and embryo survival Human Reproduction 13 178-190

Received 7 May 2003

First decision 28 July 2003.

Revised manuscript received 27 August 2003.

Accepted 12 September 2003. 